\title{
KrF Laser CVD of Chromium Oxide by Photodissociation of $\operatorname{Cr}(\mathrm{CO})_{6}$
}

\author{
P.M. Sousa ${ }^{1}$, A.J. Silvestre ${ }^{2}$, N. Popovici ${ }^{1}$, M.L. Paramês ${ }^{1}$ and O. Conde ${ }^{1 a}$ \\ ${ }^{1}$ Dep. de Física, Faculdade de Ciências da Universidade de Lisboa, 1749-016 Lisboa, Portugal \\ ${ }^{2}$ Instituto Superior de Engenharia de Lisboa, R. Cons. Emídio Navarro, 1749-014 Lisboa, Portugal
}

Keywords: Spintronic, chromium dioxide $\left(\mathrm{CrO}_{2}\right)$, Laser CVD.

\begin{abstract}
This work reports on the synthesis of chromium oxide thin films prepared by photodissociation of $\mathrm{Cr}(\mathrm{CO})_{6}$ in an oxidizing atmosphere, using a pulsed UV laser $(\mathrm{KrF}, \lambda=248 \mathrm{~nm})$. The experimental conditions which should enable the synthesis of $\mathrm{CrO}_{2}$ are discussed and results on the deposition of $\mathrm{Cr}_{\mathrm{x}} \mathrm{O}_{\mathrm{y}}$ films on $\mathrm{Al}_{2} \mathrm{O}_{3}(0001)$ substrates are presented.
\end{abstract}

\section{Introduction}

The prospect of building spintronic devices, in which electron spins are used to store and transport information, has attracted considerable attention in recent years [1-3]. Many of these proposed devices demand carefully-controlled growth of ferromagnetic/insulator or ferromagnetic/semiconductor interfaces, the development of these interfaces being one of the main technological challenges to be overcome before realistic devices can be fabricated. Chromium dioxide $\left(\mathrm{CrO}_{2}\right)$ is an attractive compound to be used in these heterostructures since it is strongly ferromagnetic at room temperature and has a half-metallic band structure fully spin-polarised at the Fermi level [4-7], making it attractive, for instance, for use in tunnel junctions with enhanced low field magnetoresistance [8] or in the fabrication of spin polarised field effect transistors [1-3]. Despite thermal CVD achievements [9-16], much effort has gone into developing efficient and controlled methods for preparing $\mathrm{CrO}_{2}$ films at sufficiently low temperatures, which are of crucial importance to ensure interface quality and the ability to coat thermal-sensitive substrates such as those envisaged for building spintronic devices (e.g. narrow gap semiconductors). Nevertheless, the synthesis of $\mathrm{CrO}_{2}$ films at low temperatures has been a difficult task due to the metastable nature of this oxide - $\mathrm{CrO}_{2}$ is metastable at atmospheric pressure and, if heated, easily decomposes into the insulating antiferromagnetic $\mathrm{Cr}_{2} \mathrm{O}_{3}$ compound, which is the most stable $\mathrm{Cr}$ oxide at ambient conditions.

Laser-assisted CVD is a selective area deposition technique which has the potential to meet the requirements stated above. In previous studies conducted in static conditions, photolytic decomposition of $\mathrm{Cr}(\mathrm{CO})_{6}$ by ultra-violet radiation at $\lambda=337 \mathrm{~nm}$ (nitrogen laser) has already led to the synthesis of films containing both $\mathrm{Cr}_{2} \mathrm{O}_{3}$ and $\mathrm{CrO}_{2}$ phases, the relative amount of these phases depending on the oxygen partial pressure used [17-20]. However, and looking for a better efficiency of the $\mathrm{Cr}(\mathrm{CO})_{6}$ photodissociation, it should be advantageous to explore dynamic atmospheres, which also allow for easy automation and continuous high-rate coating, and, on the other hand, to use other UV wavelengths, e.g. $248 \mathrm{~nm}$, for which $\mathrm{Cr}(\mathrm{CO})_{6}$ absorption cross section is much higher than for the nitrogen laser radiation [21].

It is the purpose of this paper to report on the synthesis of chromium oxide thin films on sapphire substrates, prepared by photodissociation of $\mathrm{Cr}(\mathrm{CO})_{6}$ in an oxidizing dynamic atmosphere, using a $\operatorname{KrF}$ excimer laser $(\lambda=248 \mathrm{~nm})$.

\section{Experimental approach}

Experimental set-up. The equipment used for the LCVD experiments consists of a $\mathrm{KrF}$ excimer laser, a stainless steel HV chamber, a pumping system based on a cryogenic pump and a gas sys-

\footnotetext{
${ }^{a}$ Corresponding author: Tel. + 351 217500035, Fax: +351 217573619, email: omconde@fc.ul.pt
} 
tem, which delivers the reactants into the reactor. The experimental set-up allows for dynamic and static deposition experiments.

The $\mathrm{KrF}$ laser $(\lambda=248 \mathrm{~nm}$, pulse width $=30 \mathrm{~ns})$ has a beam dimension of $24 \times 12 \mathrm{~mm}^{2}$. The laser beam impinges on the substrate at perpendicular incidence and by using an adequate optical system (lenses and masks) it is possible to control the beam spot size at the substrate level and thus the fluence reaching the substrate surface. Prior to any deposition experiment, the reactor was always evacuated to a base pressure lower than $5 \times 10^{-6}$ mbar. Chromium hexacarbonyl powder, whose vapour pressure is given by [17]

$$
\log _{10} \mathrm{P}[\text { Torr }]=10.63-3285 / \mathrm{T}[\mathrm{K}] \text {, }
$$

was used as $\mathrm{Cr}$ precursor; the $\mathrm{Cr}(\mathrm{CO})_{6}$ powder was sublimated in a controlled temperature stainless steel cell connected to the LCVD reactor. The partial pressure of $\mathrm{Cr}(\mathrm{CO})_{6}$ inside the reactor is settled by the cell temperature, the flux of the carrier gas (oxygen) and the total working pressure.

$\operatorname{Cr}(\mathrm{CO})_{6}$ photodissociation at $248 \mathrm{~nm}$. When absorbing two photons at $248 \mathrm{~nm}$, an isolated $\mathrm{Cr}(\mathrm{CO})_{6}$ molecule should decompose to $\mathrm{Cr}$ with a quantum yield given in literature as $\sim 1$ [22]. By reacting with $\mathrm{O}_{2}$, the photodissociated $\mathrm{Cr}$ would give rise to $\mathrm{CrO}_{2}$. However, the mechanism by which the photodissociation of $\operatorname{Cr}(\mathrm{CO})_{6}$ may lead to chromium dioxide is a much more complex one. The major single photoproduct formed at $248 \mathrm{~nm}$ upon dissociation of $\mathrm{Cr}(\mathrm{CO})_{6}$ is $\mathrm{Cr}(\mathrm{CO})_{4}$. At laser fluence higher than $5 \mathrm{~mJ} . \mathrm{cm}^{-2}$ secondary photodissociation of $\mathrm{Cr}(\mathrm{CO})_{4}$ to $\mathrm{Cr}$ becomes considerable $[21,22]$. But these features are only true for a very low pressure of $\mathrm{Cr}(\mathrm{CO})_{6}$, for which collisions are absent. In systems where collisions play an important role, the statistical fragmentation processes that follow the initial photodissociation event may be inhibited by collision vibrational relaxation of the photoproducts. Yet the degree of this effect is not completely known, low pressure of $\mathrm{Cr}(\mathrm{CO})_{6}$ is still considered the ideal working condition for $\mathrm{CrO}_{2}$ deposition.

To achieve the required laser fluence on the substrate it is important to quantify not only the beam energy loss on the optical components but also the energy loss due to absorption by the reactant gas mixture. Molecular oxygen absorbs UV radiation only bellow $242 \mathrm{~nm}$. This fact makes $\mathrm{Cr}(\mathrm{CO})_{6}$ vapour the major contributor to the beam absorption in the gas mixture. Chromium hexacarbonyl presents an absorption cross section $\sigma=5.3 \times 10^{-17} \mathrm{~cm}^{2}$ at $\lambda=248 \mathrm{~nm}$ [21]. By using the Beer-Lambert relation

$$
\mathrm{I}=\mathrm{I}_{\mathrm{o}} \mathrm{e}^{-\sigma \mathrm{cl}}
$$

where $\mathrm{I} / \mathrm{I}_{\mathrm{o}}$ represents the fraction of radiation transmitted in an absorption path length $1(\mathrm{~cm})$ for a given concentration $\mathrm{c}\left(\mathrm{cm}^{-3}\right)$, it is possible to calculate the fluence at the substrate surface. Fig. 1 shows the I/Io values as a function of the partial pressure of $\mathrm{Cr}(\mathrm{CO})_{6}$ for different path lengths (distance between the inner face of the chamber window used for transmission of the laser beam and the substrate surface). Based on the transmittance values it is also possible to compute the number of photons per $\mathrm{Cr}(\mathrm{CO})_{6}$ molecule, $\mathrm{n}_{v}$, at the substrate level. Fig. 2 shows the dependence of this parameter on the partial pressure of hexacarbonyl for a laser beam with a transverse section of 5.4 $\mathrm{mm}^{2}$ and energy of $31.5 \mathrm{~mJ} /$ pulse, and an absorption path length of $12 \mathrm{~cm}$. The horizontal dashedline in fig. 2 represents the threshold of two photons per $\mathrm{Cr}(\mathrm{CO})_{6}$ molecule needed to photodecompose completely the hexacarbonyl.

From figures 1 and 2 it can be concluded that ideal working conditions are those for which low partial pressures of $\mathrm{Cr}(\mathrm{CO})_{6}$ and/or small beam path lengths are selected, resulting in higher transmittance and higher number of photons per $\mathrm{Cr}(\mathrm{CO})_{6}$ molecule. 


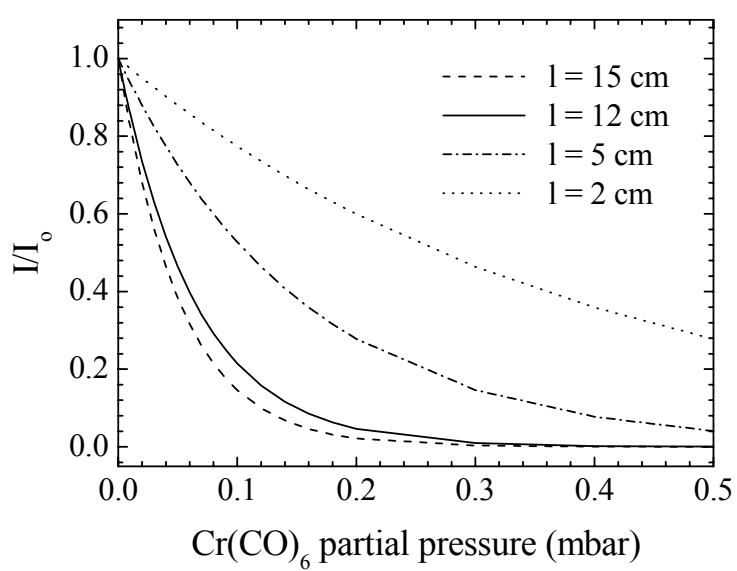

Fig. 1 - Transmittance $v s$. $\mathrm{Cr}(\mathrm{CO})_{6}$ partial pressure for several absorption path lengths.

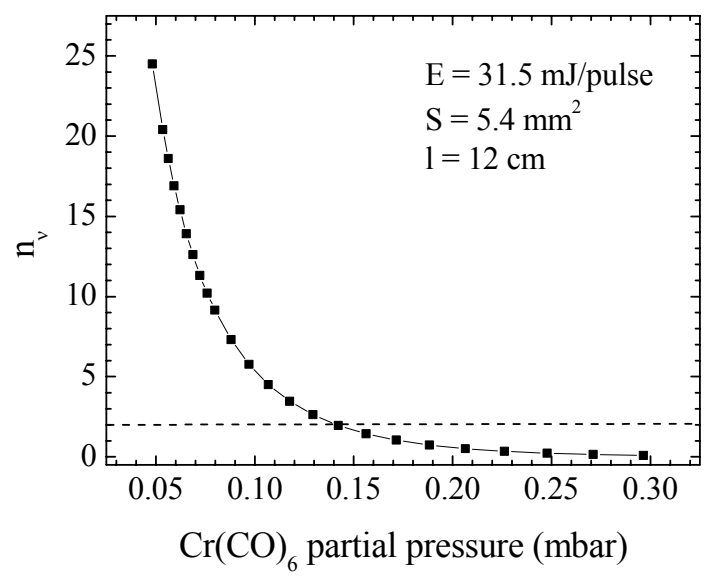

Fig. 2 - Number of photons per hexacarbonyl molecule as a function of $\mathrm{Cr}(\mathrm{CO})_{6}$ partial pressure for the given experimental conditions.

Experimental parameters and film characterization. The $\mathrm{Cr}_{\mathrm{x}} \mathrm{O}_{\mathrm{y}}$ thin films were grown at room temperature on $\mathrm{Al}_{2} \mathrm{O}_{3}(0001)$ substrates during 2 hours at a laser pulse repetition rate of $5 \mathrm{~Hz}$. Due to the geometry of our LCVD reactor it is only possible to work in gas flow mode with path lengths between 12 and $15 \mathrm{~cm}$. The overall experimental parameters used are presented in table 1 .

Table 1 - LCVD experimental conditions used to deposit the $\mathrm{Cr}_{\mathrm{x}} \mathrm{O}_{\mathrm{y}}$ thin films

\begin{tabular}{lclc}
\hline Experimental parameters & Values & Estimated parameters & Values \\
\hline \hline Beam energy, $\mathrm{E}[\mathrm{mJ}]$ & $13.5-31.5$ & Fluence at the substrate, $\mathrm{F}\left[\mathrm{mJ}^{2} \cdot \mathrm{cm}^{-2}\right]$ & $47-65$ \\
Spot area, $\mathrm{S}\left[\mathrm{mm}^{2}\right]$ & $3.6-5.4$ & $\mathrm{Cr}(\mathrm{CO})_{6}$ partial pressure, $\mathrm{p}_{\mathrm{Cr}}[\mathrm{mbar}]$ & 0.14 \\
$\mathrm{Cr}(\mathrm{CO})_{6}$ cell temperature, $\mathrm{T}_{\text {cell }}\left[{ }^{\circ} \mathrm{C}\right]$ & 10 & $\mathrm{O}_{2}$ partial pressure, $\mathrm{p}_{\mathrm{O} 2}[\mathrm{mbar}]$ & $0.07-0.11$ \\
$\mathrm{O}_{2}$ carrier flux, $\phi_{\text {carrier }}[\mathrm{sccm}]$ & 10 & Photons per $\mathrm{Cr}(\mathrm{CO})_{6}$ molecule, $\mathrm{n}_{v}$ & $0.7-2$ \\
Total pressure, $\mathrm{P}_{\mathrm{t}}[\mathrm{mbar}]$ & $0.20-0.25$ & & \\
\hline
\end{tabular}

Characterisation of the films was carried out by optical microscopy (OM), atomic force microscopy (AFM), scanning electron microscopy (SEM), energy dispersive spectroscopy (EDS), micro-Raman spectrometry and optical profilometry.

\section{Results and discussion}

Surface morphology and microstructure. The use of $\mathrm{Al}_{2} \mathrm{O}_{3}$ (0001) substrates for the growth of chromium oxide thin films should allow for a quasi-pure photolytic process since the sapphire substrates are transparent to $\mathrm{KrF}$ laser radiation. Therefore, no intense thermal contributions are expected during the synthesis of the chromium oxide. Furthermore, it is known that the use of $\mathrm{Al}_{2} \mathrm{O}_{3}$ (0001) substrates favours the growth of epitaxial $\mathrm{CrO}_{2}$ thin films [13]. OM observation revealed that the deposited films are homogeneous and exhibit a dark colour. SEM and AFM analyses of different films have shown that their morphology consists of a uniform and fine grain structure with a mean grain size of few tens of nanometers all over the deposits, as can be seen in the AFM image of fig. 3. The deposits present good adherence and are approximately rectangular in shape with thicknesses of about $100 \mathrm{~nm}$ and deposition rates $\sim 8.4 \AA . \mathrm{min}^{-1}$.

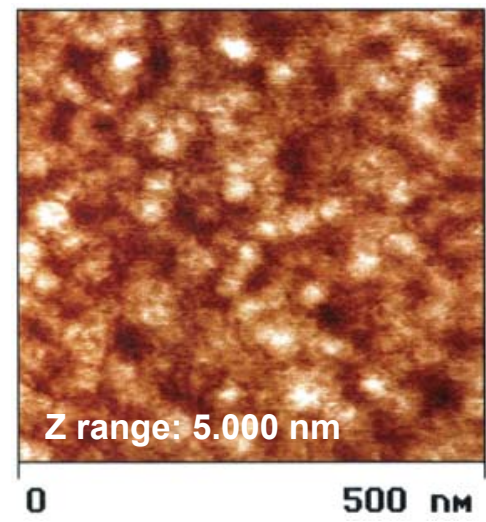

Fig. 3 - AFM image of a $\mathrm{Cr}_{\mathrm{x}} \mathrm{O}_{\mathrm{y}}$ film deposited with $\mathrm{E}=31.5 \mathrm{~mJ} /$ pulse, $\mathrm{P}_{\mathrm{t}}=0.21$ mbar, $\phi_{\text {carrier }}=10 \mathrm{sccm}$ and $\mathrm{T}_{\text {cell }}=10{ }^{\circ} \mathrm{C}$. Estimated parameters: $\mathrm{F}=65 \mathrm{~mJ} . \mathrm{cm}^{-2}$, $\mathrm{p}_{\mathrm{Cr}}=0.14$ mbar, $\mathrm{p}_{\mathrm{O} 2}=0.07$ mbar. 
Chemical and structural analysis. EDS microanalysis was performed to monitor the existence of any degree of $\mathrm{Cr}(\mathrm{CO})_{6}$ photodecomposition. The presence of chromium oxide phases was analysed by micro-Raman spectroscopy.

Fig. 4 shows these results for a film deposited with $F=65 \mathrm{~mJ} . \mathrm{cm}^{-2}, \mathrm{p}_{\mathrm{cr}}=0.14$ mbar, $\mathrm{p}_{\mathrm{O} 2}=0.07$ mbar and $\mathrm{n}_{v}=2$. The EDS spectrum in fig. 4a shows the two $\mathrm{K} \alpha(5.4 \mathrm{keV})$ and $\mathrm{K} \beta(5.9 \mathrm{keV})$ lines of $\mathrm{Cr}$, besides the $\mathrm{K} \alpha(1.48 \mathrm{keV})$ line of $\mathrm{Al}$, which confirms that decomposition of $\mathrm{Cr}(\mathrm{CO})_{6}$ was attained during the deposition process. The Raman spectrum (fig. $4 \mathrm{~b}$ ) reveals peaks that match the Raman shifts assigned to both $\mathrm{Cr}_{2} \mathrm{O}_{3}$ and $\mathrm{CrO}_{2}$ oxides [23, 24]. It should be noted that, since most of $\mathrm{CrO}_{2}$ Raman peaks overlap those of $\mathrm{Al}_{2} \mathrm{O}_{3}$ (substrate material), only the $\mathrm{B}_{2 \mathrm{~g}}\left(682 \mathrm{~cm}^{-1}\right.$ ) peak of $\mathrm{CrO}_{2}$ may be used to clearly identify the presence of this oxide phase. The synthesised chromium oxides are probably amorphous or have a low crystallinity, as suggested by the broadening of the Raman peaks.

a)

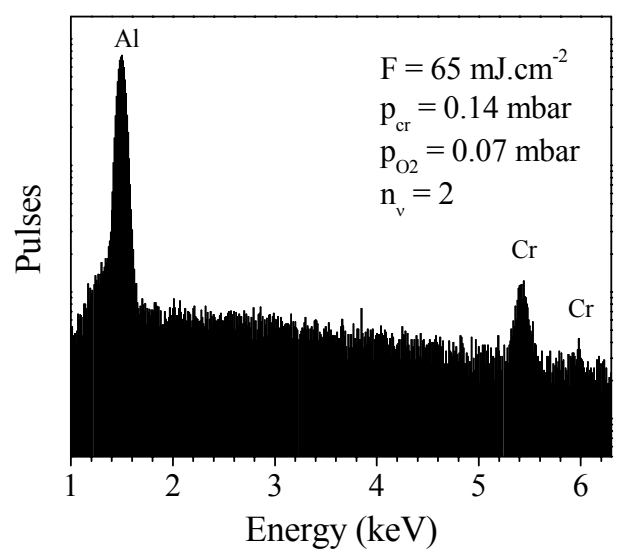

b

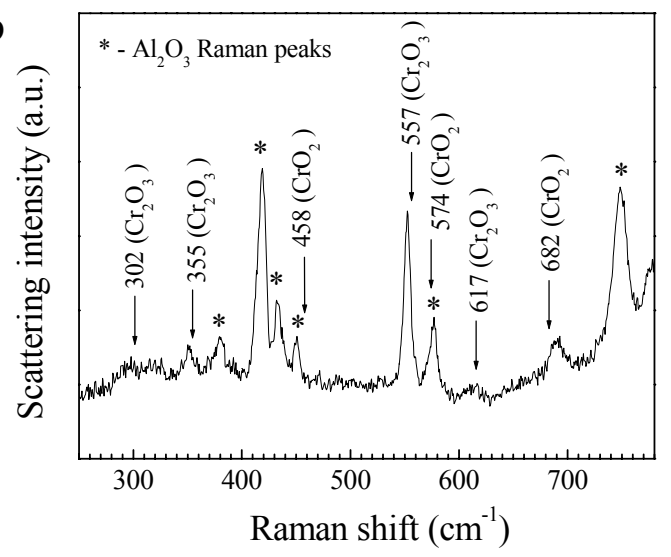

Fig. 4 -a) EDS and b) micro-Raman spectra of a film deposited with $\mathrm{E}=31.5 \mathrm{~mJ} /$ pulse, $\mathrm{P}_{\mathrm{t}}=0.21$ mbar, $\phi_{\text {carrier }}=10 \mathrm{sccm}$ and $\mathrm{T}_{\text {cell }}=10{ }^{\circ} \mathrm{C}$. The estimated parameters are those referred in a). The Raman shifts for $\mathrm{CrO}_{2}$, for $\mathrm{Cr}_{2} \mathrm{O}_{3}$ and for $\mathrm{Al}_{2} \mathrm{O}_{3}$ are indicated. a)

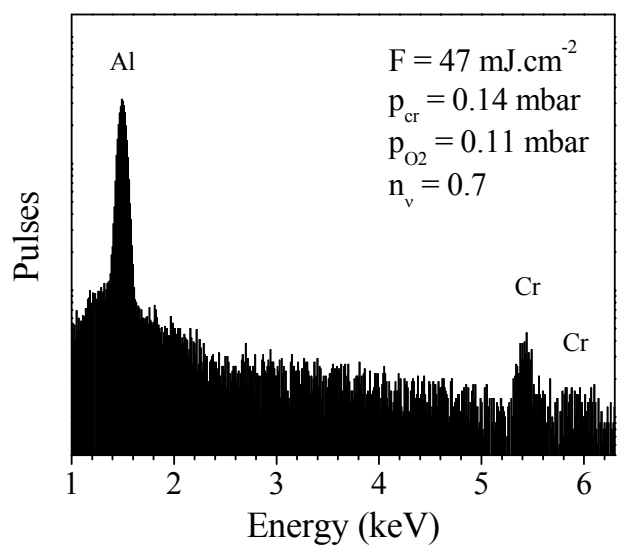

b

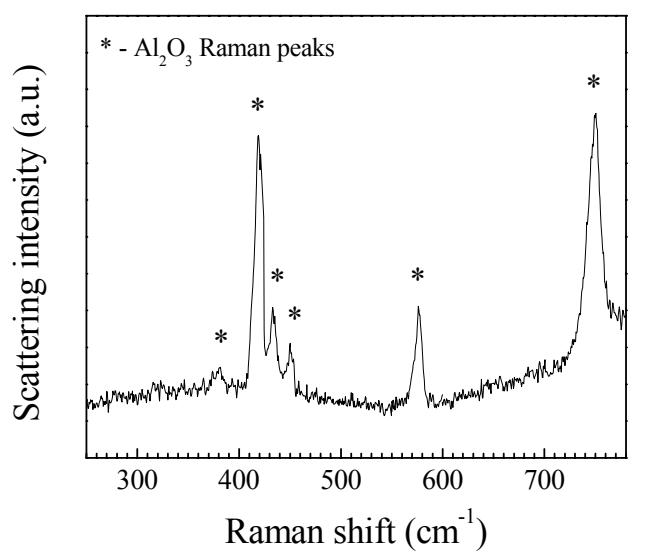

Fig. 5 -a) EDS and b) micro-Raman spectra of a film deposited with $\mathrm{E}=13.5 \mathrm{~mJ} /$ pulse, $\mathrm{P}_{\mathrm{t}}=0.25$ mbar, $\phi_{\text {carrier }}=10 \mathrm{sccm}$ and $\mathrm{T}_{\text {cell }}=10^{\circ} \mathrm{C}$. The estimated parameters are those referred in a). The Raman shifts for $\mathrm{Al}_{2} \mathrm{O}_{3}$ are indicated.

By keeping constant the partial pressure of $\mathrm{Cr}(\mathrm{CO})_{6}$ and decreasing the laser fluence at the substrate surface, which implies $\mathrm{n}_{v}<2$, the photolytic decomposition of $\mathrm{Cr}(\mathrm{CO})_{6}$ still occurs but no chromium oxide phases were obtained, even when the partial pressure of oxygen was increased, as can be seen from the two spectra of fig. 5, recorded over a film deposited with $\mathrm{F}=47 \mathrm{~mJ} . \mathrm{cm}^{-2}$, $\mathrm{p}_{\mathrm{cr}}=0.14$ mbar, $\mathrm{p}_{\mathrm{O} 2}=0.11 \mathrm{mbar}$ and $\mathrm{n}_{v}=0.7$. As for the film of fig. 4 , the EDS spectrum of this film (fig. 5a) also shows the two lines of Cr; however the Raman spectrum (fig.5b) reveals no other peaks than those matched by the Raman shifts assigned to $\mathrm{Al}_{2} \mathrm{O}_{3}$. Therefore, chromium oxide formation did not occur showing that $\mathrm{n}_{v}=0.7$ is clearly lower than the value needed to photodecom- 
pose completely the hexacarbonyl. Consequently, the chromium present in the deposited material (fig. 5a) can only be due to the adsorbed $\mathrm{Cr}(\mathrm{CO})_{\mathrm{x}}$ photofragments resulting from the incomplete $\mathrm{Cr}(\mathrm{CO})_{6}$ decomposition during the deposition process.

Dowben and co-workers [17-20] have pointed out that the partial pressure of oxygen is the prominent parameter to be controlled in order to achieve $\mathrm{CrO}_{2}$ growth by UV laser photodissociation of $\mathrm{Cr}(\mathrm{CO})_{6}$, for a given partial pressure of this precursor $\left(10^{-5} \mathrm{Torr}\right)$. Our results, which were obtained for higher $\mathrm{Cr}(\mathrm{CO})_{6}$ partial pressure although in the same range of $\mathrm{p}_{\mathrm{Cr}} / \mathrm{p}_{\mathrm{O} 2}$ as in ref. [17-20], show that the number of photons available per $\mathrm{Cr}$ precursor molecule is the crucial parameter to achieve $\mathrm{CrO}_{2}$ deposition. In fact, $\mathrm{n}_{v}$ summarises the effect of both $\mathrm{Cr}(\mathrm{CO})_{6}$ partial pressure and laser fluence.

\section{Conclusions}

In this paper, it was shown that $\mathrm{Cr}(\mathrm{CO})_{6}$ can be a suitable precursor for the $\mathrm{KrF}$ laser-assisted CVD of chromium oxide. Thin films with good adherence, fine grain structure and containing both $\mathrm{Cr}_{2} \mathrm{O}_{3}$ and $\mathrm{CrO}_{2}$ oxide phases were obtained. It was also shown that the number of photons per hexacarbonyl molecule is a crucial experimental parameter in the $\mathrm{KrF}$ laser photodissociation of $\mathrm{Cr}(\mathrm{CO})_{6}$ towards synthesis of chromium dioxide. Further experimental work is currently being done in order to tune the experimental conditions that will lead to pure chromium dioxide deposition.

\section{Acknowledgements}

This work is supported by the EU contract FENIKS: G5RD-CT-2001-00535.

\section{References}

[1] G.A. Prinz, Physics Today Vol. 48 No. 4 (1995), p. 58.

[2] D. Grundler, G.A. Prinz, Science Vol. 282 (1998), p. 1660.

[3] D. Grundler, Physics World Vol. 15 No. 4 (2002), p. 39.

[4] K.J. Schwartz, J. Phys. F: Met. Phys. Vol. 16 (1986), p. L211.

[5] M.A. Korotin, V.I. Anisimov, D.I. Khomskii and G.A. Sawatzki, Phys. Rev. Lett. Vol. 80 (1998), p. 4305.

[6] R.J. Soulen Jr., J. M. Byers, M.S. Osofsky, B. Nadgorny, T. Ambrose, S.F. Cheng, P.R. Broussard, C.T. Tanaka, J. Nowak, J.S. Moodera, A. Barry, and J.M.D. Coey, Science Vol. 282 (1998), p. 85.

[7] Y. Ji, G.J. Strijkers, F.Y. Yang, C.L. Chien, J.M. Byers, A. Anguelouch, G. Xiao and A. Gupta, Phys. Rev. Lett. Vol. 86 (2001), p. 5585.

[8] A.M. Bratkovky, Phys. Rev. B Vol. 56 (1997), p. 2344.

[9] S. Ishibashi, T. Namikawa and M. Satou, Jpn. J. Apll. Phys. Vol. 17 (1978), p. 249.

[10] S. Ishibashi, T. Namikawa and M. Satou, Mater. Res. Bull. Vol. 14 (19878), p. 51.

[11] K. Suzuki and P.M. Tedraw, Phys. Rev B Vol. 58 (1998), p. 11597.

[12] K. Suzuki and P.M. Tedraw, Apll. Phys. Lett. Vol. 74 (1999), p. 428.

[13] X.W. Li, A. Gupta, T.R. McGuire, P.R. Duncombe and G. Xiao, J. Appl. Phys. Vol. 85 (1999), p. 5585.

[14] X.W. Li, A. Gupta and G. Xiao, Appl. Phys. Lett. Vol. 75 (1999), p. 713.

[15] A. Gupta, X.W. Li, S. Guha and G. Xiao, Appl. Phys. Lett. Vol. 75 (1999), p. 2996.

[16] M. Rabe, J. Pommer, K. Samm, B. Özyilmaz, C. König, M. Fraune, U. Rüdiger, G. Güntherodt, S. Senz and D. Hess, J. Phys.: Condens. Matter Vol. 4 (2002), p. 7.

[17] P.A. Dowben, Y.G. Kim, S. Baral-Tosh, G.O. Ramseyer, C. Hwang and M. Onellion, J. Appl. Phys. Vol. 67 (1990), p. 5658.

[18] F.K. Perkins, C. Hwang, M. Onllion, Y.-G. Kim and P.A. Dowben, Thin Solid Films Vol. 198 (1991), p. 317.

[19] R. Cheng, C.N. Borca and P.A. Dowben, Mat. Res. Soc. Symp. Proc. Vol. 614 (2000), p. F10.4.1.

[20] R. Cheng, C.N. Borca, P.A. Dowben, S. Stadler and Y.U. Idzerda, Appl. Phys. Lett. Vol. 78 (2001), p. 521.

[21] M. Rothschild, in Laser Microfabrication: Thin Film Processes and Lithography, D.J. Ehrlich and J.Y. Tsao (Eds.), Academic Press, Boston, 1989, p.163.

[22] G.W. Tyndall and R.L. Jackson, J. Chem. Phys. Vol. 91 (1989), p. 2881.

[23] J. Zuo, C. Xu, B. Hou, C. Wang, Y. Xie and Y. Qian, J. Raman Spectrosc. Vol. 27 (1996), p. 921.

[24] M.N. Lliev, A.P. Litvinchuk, H.-G. Lee and C.W. Chu, Phys. Rev. B Vol. 60 (1999), p. 33. 